\title{
Longtail tuna fisheries in the northern Arabian Sea off the north-west coast of India: Moving towards developing spatially explicit fisheries management strategy
}

\author{
K. MOHAMMED KOYA ${ }^{1}$, PRATHIBHA RROHIT ${ }^{2}$, E. M. ABDUSSAMAD ${ }^{1}$, \\ VINAY KUMAR VASE ${ }^{3}$ AND A. P. DINESHBABU ${ }^{2}$ \\ ${ }^{1}$ ICAR-Central Marine Fisheries Research Institute, Ernakulam North P. O., Kochi - 682018 , Kerala, India \\ ${ }^{2}$ Mangalore Research Centre of ICAR-Central Marine Fisheries Research Institute, Mangaluru - 575001 \\ Karnataka, India \\ ${ }^{3}$ Veraval Regional Centre of ICAR-Central Marine Fisheries Research Institute, Bhidiya Plot, Veraval - 362269 \\ Gujarat, India \\ e-mail:koya313@gmail.com
}

\section{ABSTRACT}

Longtail tuna (Thunnus tonggol, Bleeker, 1851), the largest growing species among neritic tunas have a unique distribution pattern globally. Northern Arabian Sea together with the Oman Sea and Persian Gulf in the north-western Indian Ocean is considered to be the major area where the species is abundant and form sizeable fisheries globally. India has an artisanal tuna fishery and contributes nearly $10 \%$ of the longtail tuna landing in the region, with Gujarat alone contributing nearly $80 \%$. The paper updates on the longtail tuna fisheries in the region with focus on the north-west coast of India together with its spatial characteristics. Clues on the areas of abundance of the species along Gujarat coast over the seasons and temporal movements of different ontogenetic stages in the shelf areas are revealed. The study sets prelude to a cost effective and participatory collection of spatially referred data on the artisanal and small scale fisheries in the region.

Keywords: Longtail tuna, North-west coast of India, Northern Arabian Sea, Spatial distribution

\section{Introduction}

Longtail tuna (LOT), Thunnus tonggol (Bleeker, 1851) has an exceptional pattern of distribution and standing in tuna fisheries globally. Its distribution is limited to the tropical belt in the northern hemisphere along the Indo-West Pacific from Japan through the Philippines to Papua New Guinea to northern Australia, west through the East Indies, India, Middle East Asia upto the horn of Africa (Collette and Nauen, 1983). Though nearly 17 countries in the Indo-Pacific exploit the resource (Yesaki, 1991), it forms a relatively significant component of tuna fisheries in only a few countries. The major fisheries for the longtail tuna globally include the purse seine fishery in the South China Sea by Malaysia, Thailand, Taiwan and Indonesia and the gillnet fishery in the northern Arabian Sea by Iran, Oman, Pakistan, India and Yemen (Yesaki, 1989). Thailand, Indonesia, Malaysia and Iran contribute most to reported annual landings.

Intricacies of variations in fishery performance among the regions and different sub-regions are not fully known. The northern Arabian Sea is one region where this species constitutes a considerable commercial fishery. However, there is substantial difference in its exploitation among the countries in the region in terms of quantity, pattern of exploitation and scale of operation. The Indian Ocean Tuna Commission (IOTC, 2017) notified the stock to be both overfished and subject to overfishing as per 2015 data and emphasised the need for collecting/collating additional information on the fisheries, catch rates, size composition and life history traits by the members and the cooperating non-contracting parties (CPCs) of IOTC. Information on the movement of the species at regional as well as at intraregion level is of utmost importance for arriving at clearer picture for devising regional management strategies. This study was therefore undertaken to update the longtail tuna fishery in the northern Arabian Sea with special reference to the north-west coast of India, with details on catch rates, size composition and spatio-temporal movement of the fish using spatially referred catch data collected with voluntary participation of fishermen.

\section{Materials and methods}

Data on catch, effort, length frequency and biological aspects were collected from important fishing harbours in Gujarat (Veraval: 205․00 N; 70²1.43E, Mangrol: 
$21^{\circ} 06.29 \mathrm{~N} ; \quad 70^{\circ} 06.04 \mathrm{E}$ and Porbander: $21^{\circ} 38.17 \mathrm{~N}$; $69^{\circ} 35.15 \mathrm{E}$ ) (Fig. 1). Details on various aspects of fishing andhandling were gathered from the fishers through enquiry. Monthly and annual catch and effort data of the longtail tuna collected by the Fisheries Resources Assessment Division of ICAR-Central Marine Fisheries Research Institute (ICAR-CMFRI) and maintained at the National Marine Fishery Data Centre (NMFDC), Kochi was used for studying the historic performance of the longtail tuna fishery of Gujarat (1985-2017). Biological data on length composition of the tuna fishery in the province of Gujarat for the decade spanning 2006 to 2016, collected and maintained at the Regional Centre of ICARCMFRI at Veraval was used for various analyses. Nominal catch data extracted from the IOTC Secretariat database was used for intra-region comparisons. The average catch (2006-2015) was plotted against the Continental Shelf (CS) area of the countries in the region [as available in Food Agricultural Organisation (FAO) Fishery and Aquaculture Country Profile (online) cited on 5 February, 2018] to understand if the expanse of suitable habitat influences the catch. Along the Indian coast, the CS area constituted by Gujarat and Maharashtra, provinces along the north-west coast of India were only considered.

Specially designed and pre-tested logsheets were provided to three medium-sized commercial multiday gillnetters (16 m OAL) operating off Veraval who volunteered to record and provide data. Veraval is the major fishing harbour for large-mesh gillnetter based fishing in the region. The logsheet was designed to gather maximum information on fishing grounds, time and duration of operation, number of hauls, size-wise catch and species composition. The schedule had fields to note the date, Global Positioning System (GPS) points for shooting and hauling the net, species composition as well as for number of fishes under the size classes of small $(<40 \mathrm{~cm})$, medium $(40-60 \mathrm{~cm})$ and large $(>60 \mathrm{~cm})$ for the listed species. The fishermen of selected gillnetters were provided with the logsheets before every voyage and the filled in schedules were collected back after the fishing voyage. Relative accuracy of the position data was checked for the correctness using Google Earth and the outliers found were omitted from the database. Accuracy of the data were also ascertained through port based observations and periodic consultation with the participating fishermen. Data schedules for 567 days were collected during the study period (January 2011 to December 2016) covering all fishing months. Marine fishing is customarily prohibited in the state during June-August, coinciding with the south-west monsoon.

GeoMedia Professional 2014 and its extensions were used to create georeferenced maps for the abundance and disribution of Thunnus tonggol. The data collected were entered in an MS excel 1997-2003 format compatible

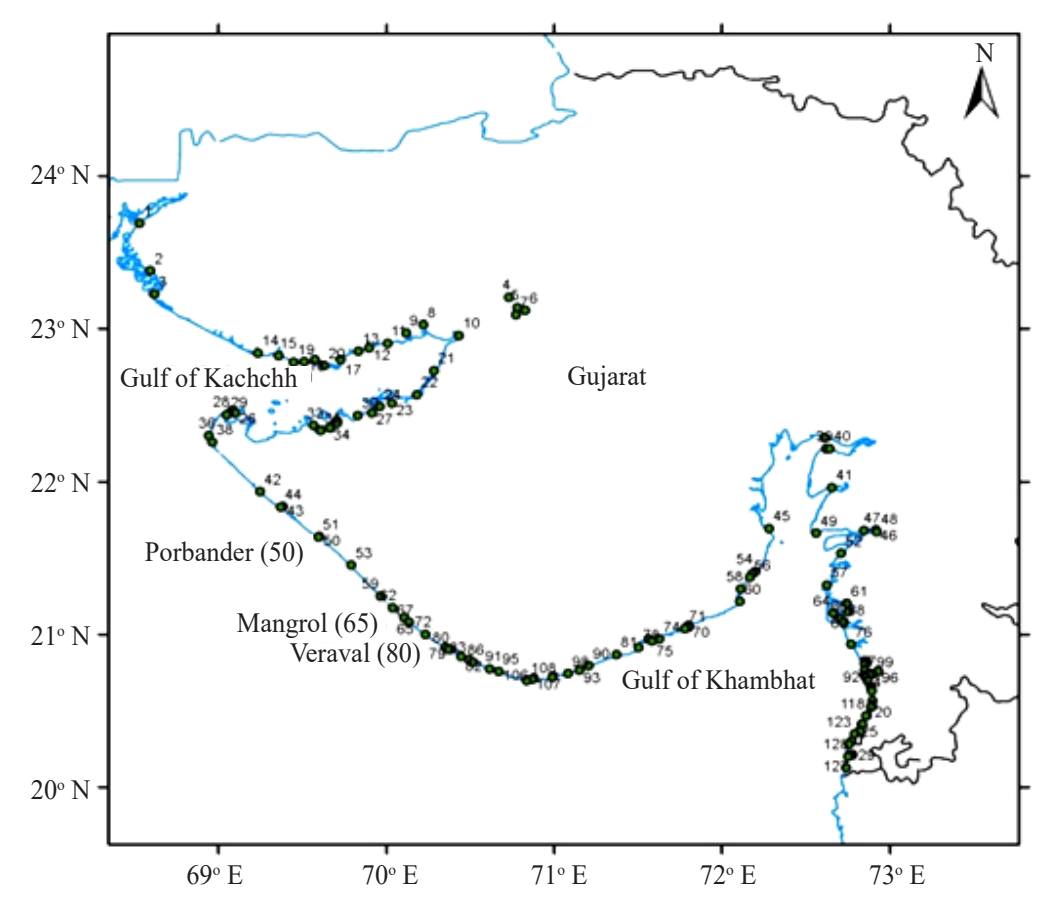

Fig. 1. Map of Gujarat, India showing the two gulfs (Gulf of Kachch and Gulf of Khambhat), 129 fishing harbours /landing centers and the major fishing harbours for Tuna fisheries (Veraval, Mangrol and Porbander) 
to GeoMedia Professional 2014 GIS platform as followed by Azeez et al. (2016). Coastline and bathymetry maps were digitised from available nuatical maps and saved in shapefile format (.shp). Interpolations were made using geostatistics (Rivoirard et al., 2000). Analyses were performed to create different maps depicting the extent of the gillnet fishery, extent of longtail tuna fishing grounds and seasonal changes in the abundance pattern with respect to different size classes in the region.

\section{Results}

Longatail tuna (LOT) fisheries in the northern Arabian Sea

Results of analysis of the nominal catches by the different countries in the northern Arabian Sea (AS) during 1996 to 2016 is given in Fig. 2. Iran with an average landing of 40, $0032 \mathrm{t}$ was the major contributor followed by Pakistan (10,541 t), Oman (8304 t), India (7176 t) and Yemen $(4186 \mathrm{t})$. These countries together constituted nearly $73 \%$ of the LOT landing in Indian Ocean and nearly $99 \%$ of the landing in the northern Arabian Sea during 2016. The results (Fig. 3) indicated that the CS area of India is the highest (29.6 lakh sq. km) while the highest catch of LOT was by Iran. Pakistan and Yemen also had higher proportion of catch in comparison to the CS area in possession. The north-west coast of India constitutes over $60 \%$ of the continental shelf of the country.

\section{LOT fisheries in India}

Longtail tuna landing in India ranged from $109 \mathrm{t}$ in 1986 to 13,926 t in 2012 and depicted a linear increasing trend during the period (Fig. 4). LOT landing increased steeply since 1990 s to reach a peak in 2000 followed by a fall in 2003 and 2009. Thereafter, the landing increased to reach the highest ever in 2012. In India, the west coast contributed $99.9 \%$ of the catch with Gujarat alone

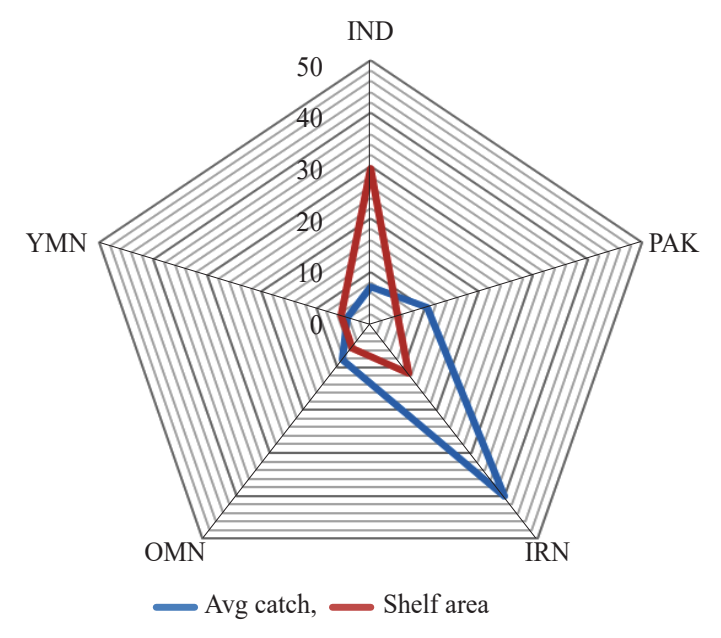

Fig. 3. LOT landing by countries in the Northern Arabian Sea vs their Continental Shelf area. IND: India, OMN: Oman, PAK: Pakistan, YEM: Yemen, IRN: Iran

constituting $79 \%$. The catch by Gujarat and Maharashtra together (north-west coast) constituted nearly $93 \%$ of the LOT catch (Fig. 5). Hence the LOT catch made along the north-west coast dictated the landing trend of the species in the country.

\section{LOT fisheries in Gujarat}

Perusal of the dominant species contributing to the tuna fishery in Gujarat since 1985 (Fig. 6) revealed that LOT did not form part of the total tuna catch till 1990 and kawakawa and bullet tunas were the major tuna species forming the catch. However, since 1991 LOT has been the prominent tuna species landed in Gujarat and on an average formed $53 \%$ of the total tuna landings. LOT landings by gillnetters (pooled effort for outboard gillnetter and mechanised gillnetters) in the State registered a steady increase over the years, despite fluctuations in some years,

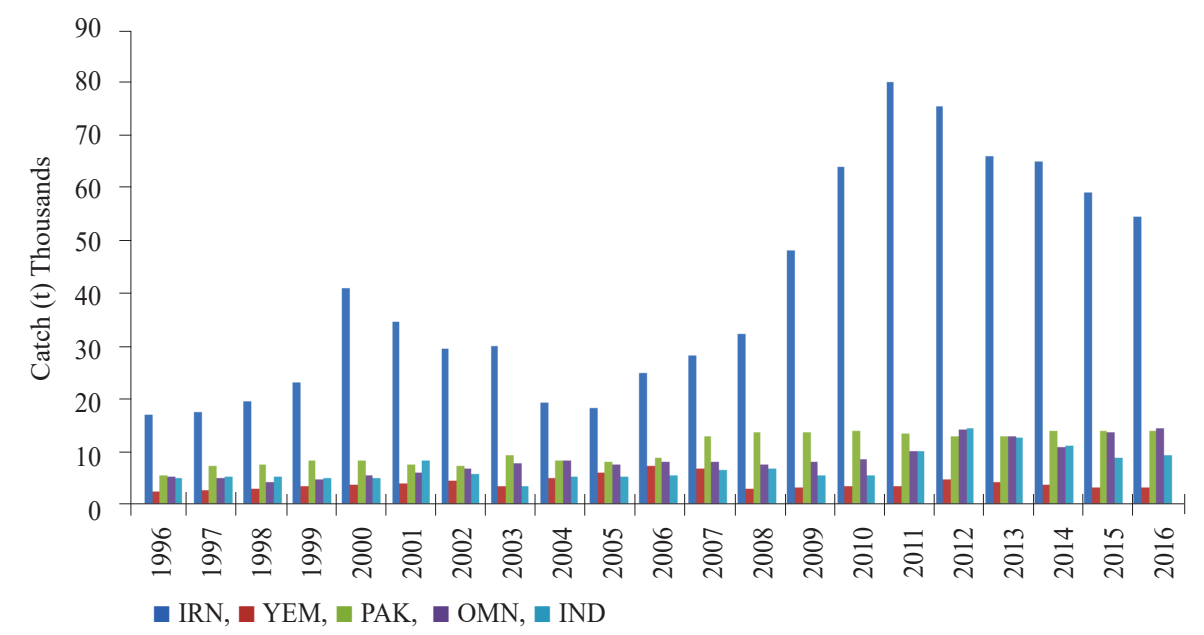

Fig. 2. Trend of LOT landing by countries in the northern Arabian Sea. IND: India, OMN: Oman, PAK: Pakistan, YEM: Yemen, IRN: Iran 


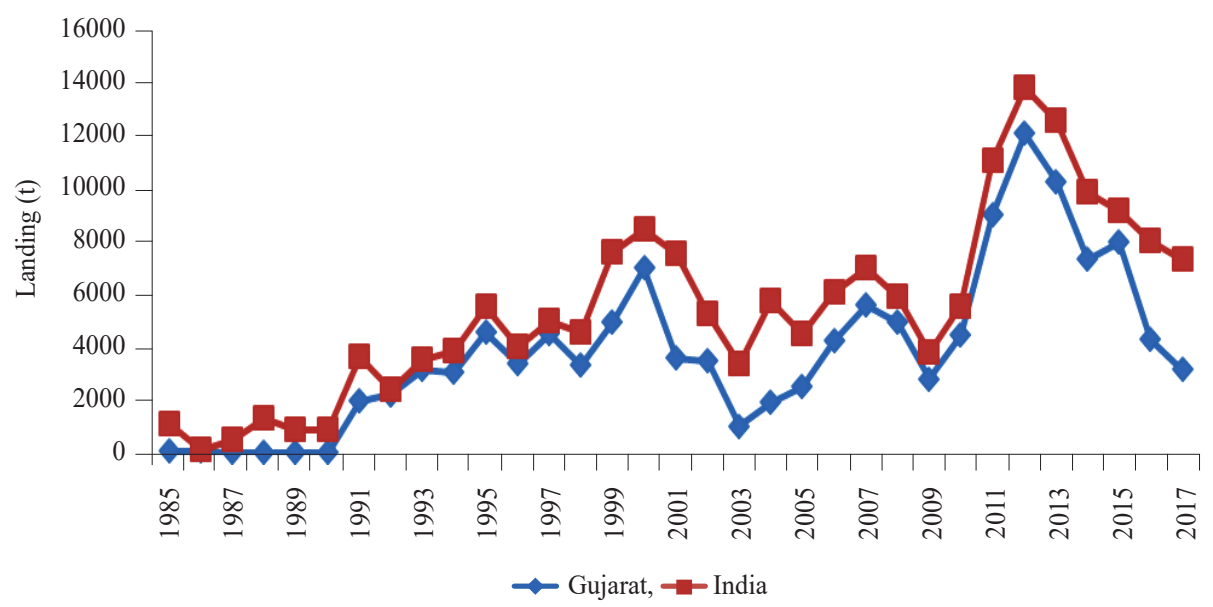

Fig. 4. Trend of LOT landing in India and Gujarat (1985-2017)

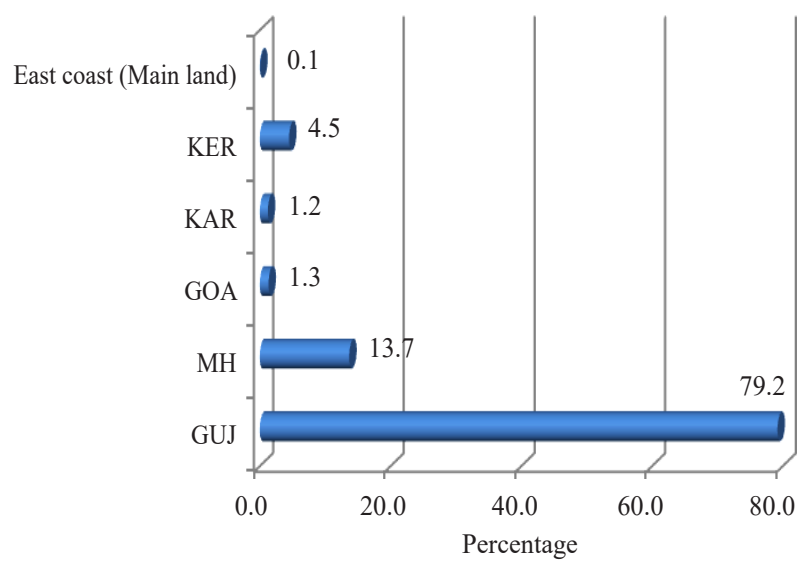

Fig. 5. LOT landing in different provinces of India GUJ: Gujarat, MH: Maharashtra, GOA: Goa, KAR: Karnataka, KER: Kerala, East coast (Mainland): excluding Andaman and Nicobar Islands (\% of Average 1985-2016) with the catch ranging from a mere $1 \mathrm{t}$ in 1989 to 12,136 $\mathrm{t}$ in 2012 (Fig.7). The LOT landing almost doubled in the five years period during 2010-14 mainly due to the spurt in landing during 2012.

Linear trend line fitted to decadal landing of the LOTs during 1989 to 2014 depicted an increasing trend during 1989-1994, a decreasing trend during 1995-2004 and again an increasing trend during 2005 to 2014 (Fig. 8). The catch rate analysed for the last 10 years (2006-15) depicted an upward trend with inter-annual variations. Catch and the catch rate (Fig. 9) followed a similar pattern. However, highest catch rate was during 2011 though the highest catch was recorded during 2012. Increase in fishing effort was evident consequent to an exceedingly good catch in 2011 leading to further increase in catch in 2012 but with a lower catch rate. The catch and catch rate continued to decline there after till 2016.

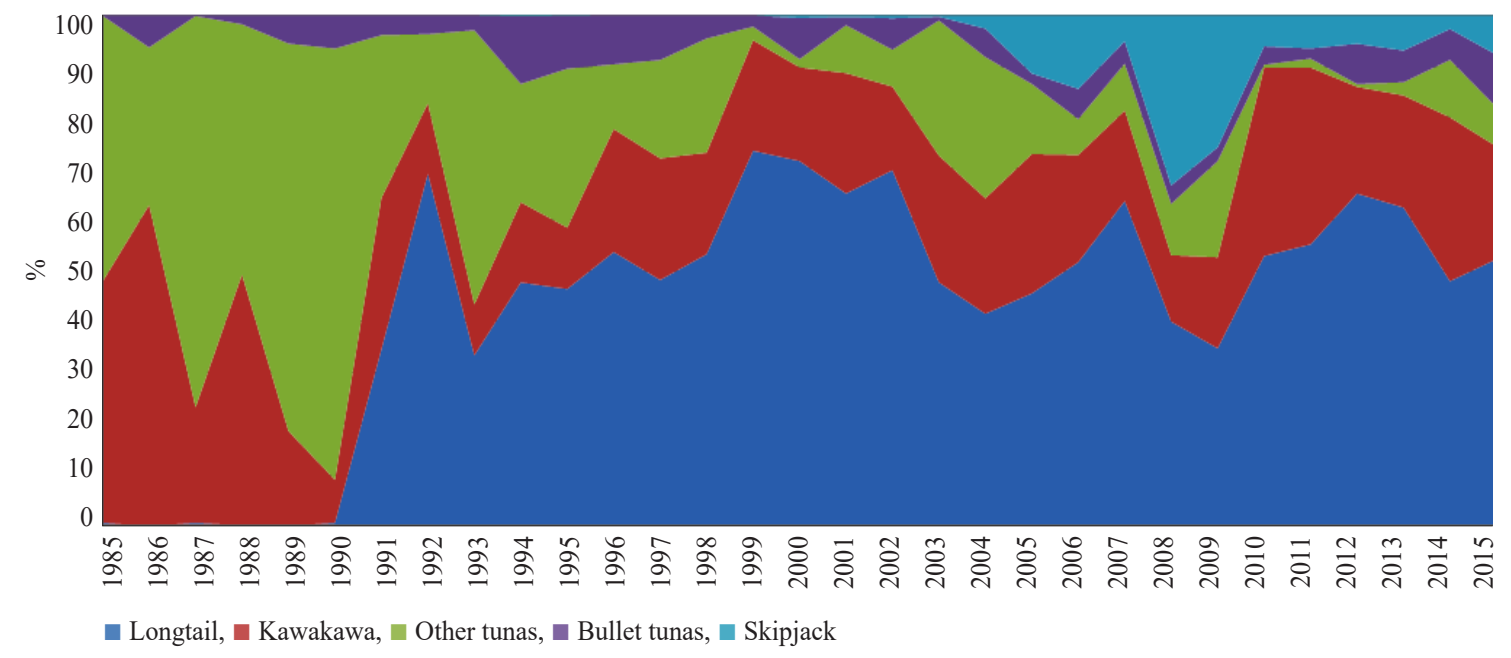

Fig. 6. Percentage composition of tuna fisheries in Gujarat since 1985 


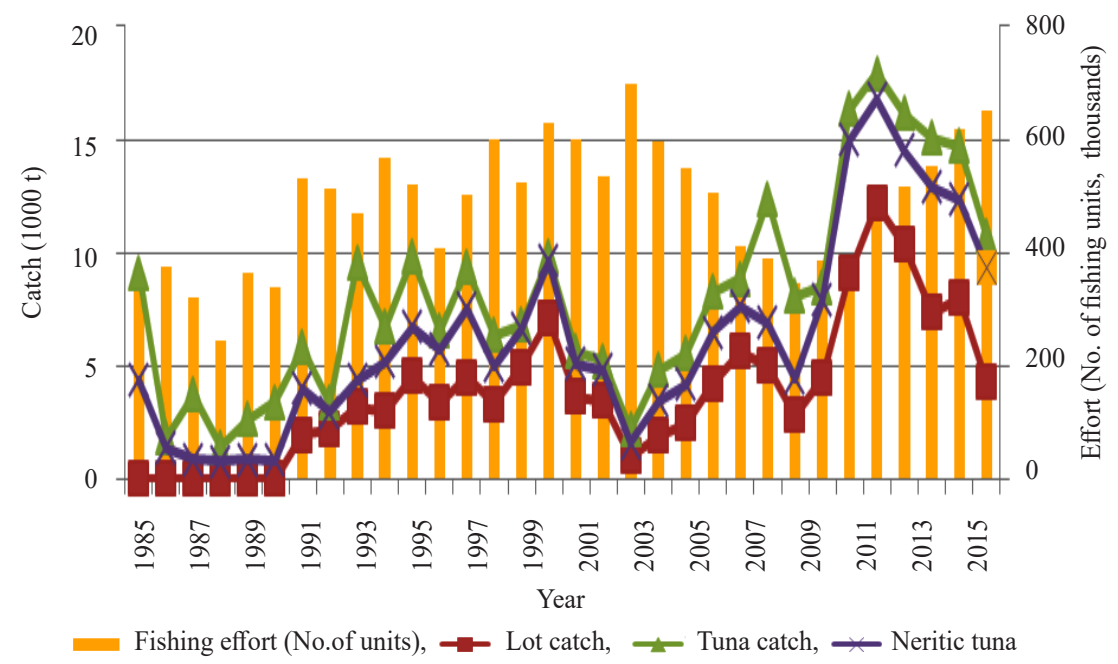

Fig. 7. Annual Catch of tunas (all tunas), neritic tunas (all neritic species) and LOT against the effort (Large-mesh gillnet)

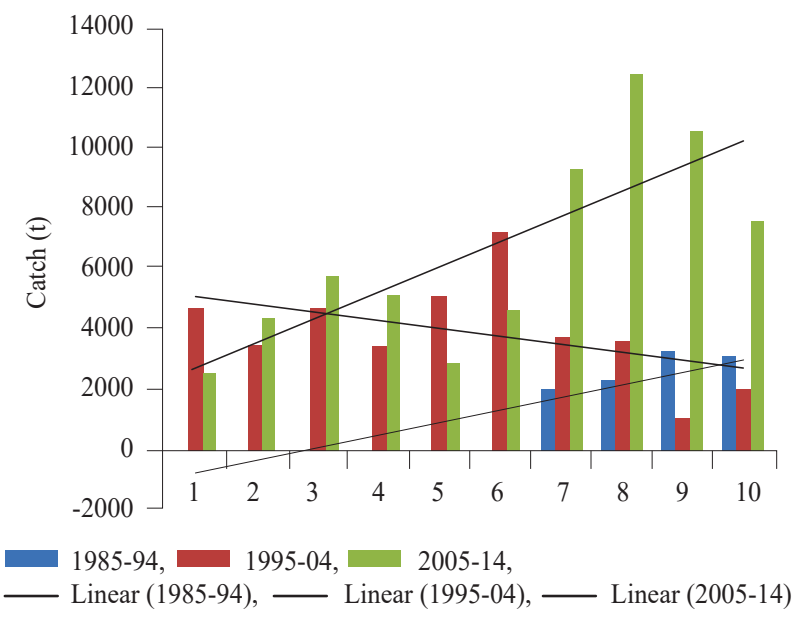

Fig. 8. Decadal trend of LOT landing in Gujarat (1985-2014)

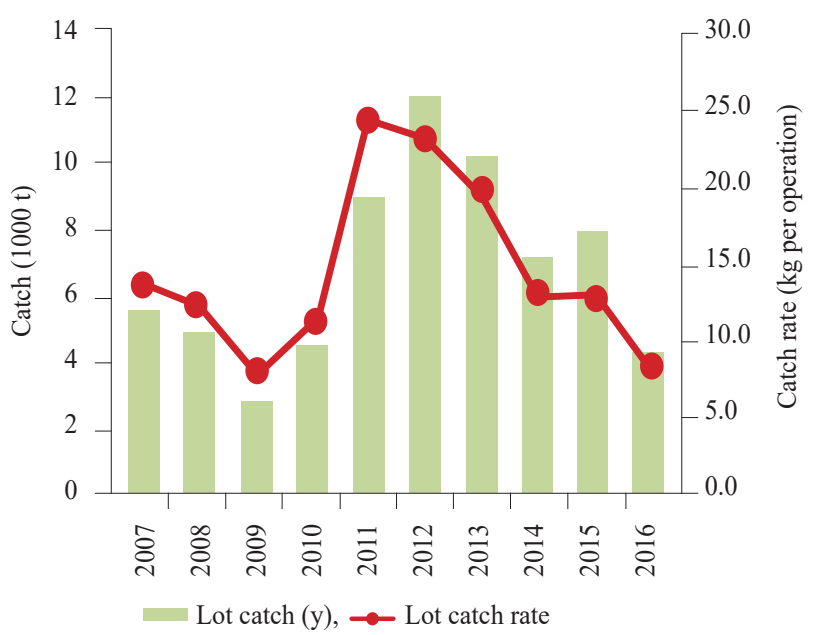

Fig. 9. Catch and catch rate of LOT in gillnets in Gujarat during 2007-16
Monthly observations on landing of LOT in Gujarat during the past 10 years (2007-2016) showed that LOT formed part of tuna catch in all months (Fig. 10) of the fishing season. Fishing season in the state commenced in September after the seasonal closure during June-August coinciding with the south-west monsoon and continued till May. The major peak in landing was observed in February and minor peak in October. Lowest landing was recorded during May.

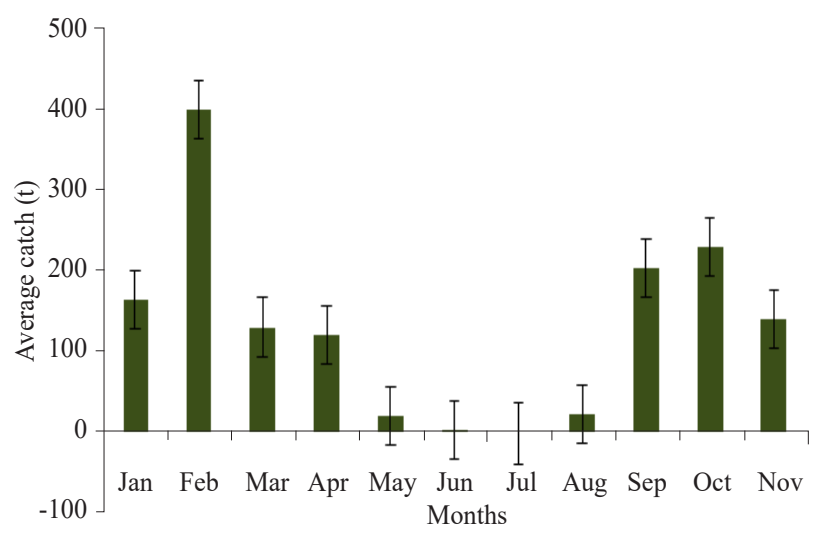

Fig. 10. Month-wise LOT landing in Gujarat (Average for 2006-16). Error bars indicate Standard Error

\section{Craft and gear involved in the fisheries}

There are basically 2 types of crafts in vogue in the gillnet fisheries of Gujarat: (i) FRP canoes of 9-12 m OAL fitted with outboard motor or inboard diesel engine [Outboard gillnetter (OBGN)] but without proper wheel house and (ii) Wooden or FRP 16-17 m OAL craft with inboard engine, proper wheel house and deck [Mechanised gillnetter (MGN)] (Fig. 11). These mechanised units have a fish-hold of 4-6 $t$ and endurance up to 10 days. The net is 


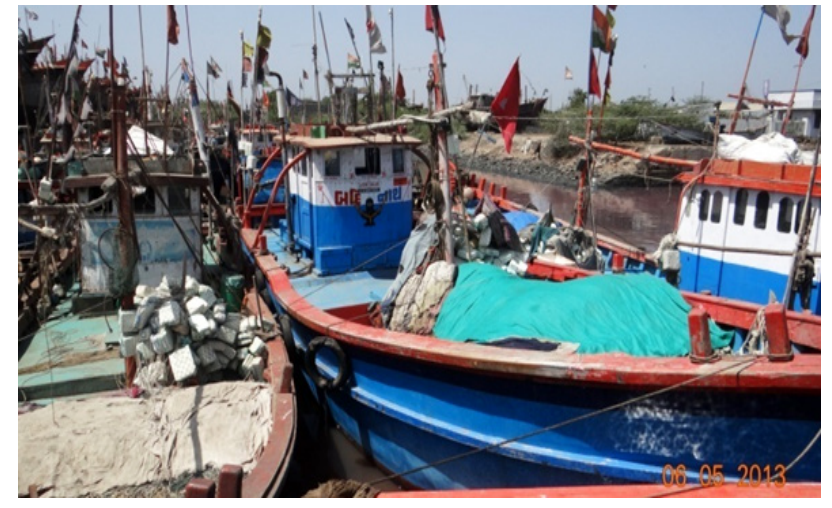

(a)

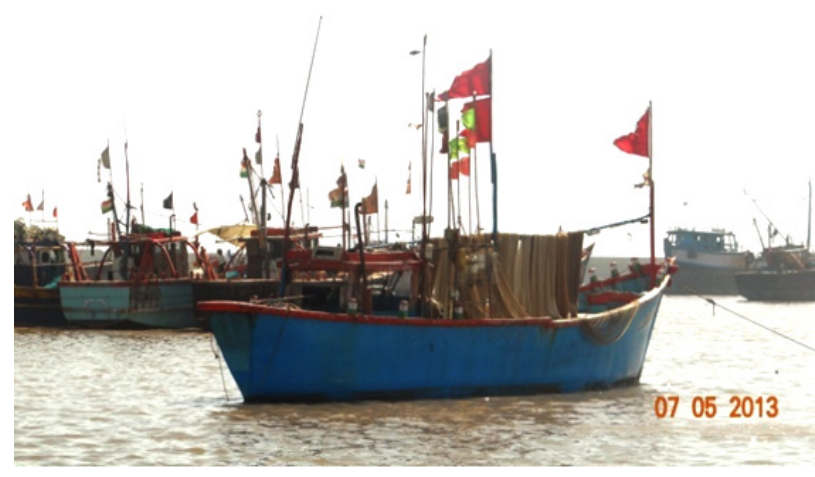

(b)

Fig. 11. Large (a) and small (b) fishing crafts in vogue in gillnet fisheries of Gujarat

made of multifilament nylon (Polyamide) net with a mesh size ranging from $80-140 \mathrm{~mm}$. The total length ranged from 5000-7000 $\mathrm{m}$ in length and depth from 15-20 m. Increased rate of replacement of smaller fishing vessels with larger ones was noticed since 2008-09. Fishing duration varied from 3-5 days in smaller craft to 6-8 days in the larger crafts. Tunas including LOT are also caught by troll lines operated by most of the motorised crafts operating gillnets and trawls while steering to their fishing grounds or while shifting fishing grounds. Though segregating the gillnet catch and troll line catch is very difficult in gillnetters; the LOT landed by trawlers invariably could be categorised as troll line caught as the tunas seldom incident in trawl nets. However, it is learnt that some trawlers also carry gillnets and use it when the trawl catch is poor. Operational limits of the OBM crafts and MGN sometimes overlap; however, the former units operate in the inshore areas $<100 \mathrm{~m}$ depth zones while the latter operate up to and beyond $200 \mathrm{~m}$ depth zone. OBM crafts constituted $68 \%$ of the landing while the mechanised gillnetters formed $29 \%$ and other gears together formed $4 \%$. The tuna landing by mechanised gillnetters in the past five years have recorded a steep increase (Fig. 12).

\section{Size composition in LOT fisheries in Gujarat}

Size composition in the LOT landed in Gujarat during 2008 to 2015 was analysed. The fork length (FL) ranged from $258 \mathrm{~mm}$ in November, 2013 to $819 \mathrm{~mm}$ in September, 2014 with the mean size at $589 \mathrm{~mm}$. Most $(80 \%)$ of the fishes caught were in the size range of 500 to $700 \mathrm{~mm}$ (Fig. 13). Annual mean, minimum and maximum length over the years during the study period is given in Fig. 14. Seasonal variations in size were not observed (Fig. 15). Mean length was lowest during post-monsoon and highest during winter. Maximum sizes in all the three seasons were almost close to each other with post-monsoon having the highest size with wider size range followed by winter.

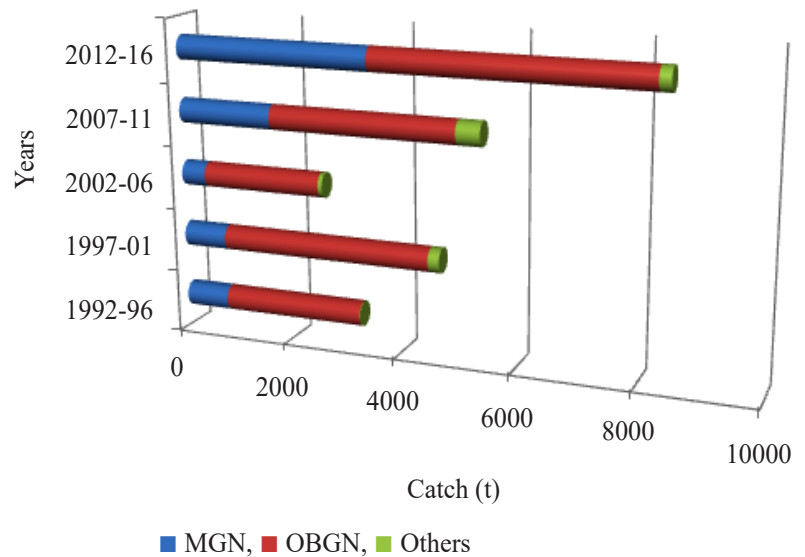

Fig. 12. Craft-gear combinations in longtail tuna fisheries of Gujarat (Five year average catch from 1992-2016). MGN-Mechanised gllnet; OBGN-Outboard gillnet; OTHERS-Other gears

\section{Spatial variation in longtail tuna abundance}

The large-meshed gillnet fishery targets the large pelagic fishes such as the neritic and oceanic tunas, mahimahi, cobia, pelagic sharks and file fishes. In Gujarat, this fishery is largely based at the fishing ports in Veraval, Mangrol and Vanakbara (Fig. 16), which indicates the extent of fishing area by the large-mesh gillnetters of Gujarat as well as the variation in catch rates. The fishing effort extended all along the Gujarat coast right from the northern most border of the India's EEZ to off south Gujarat from $10 \mathrm{~m}$ to beyond $200 \mathrm{~m}$ depth zones. This region is within the Indian EEZ and largely concentrated in the shelf areas of Gujarat. The catch rates in the gillnetters were higher between 30 to $100 \mathrm{~m}$ depth zone off the Kathiawad Peninsula from Okha to Vanakbara.

Neritic tunas were the most dominant catch in the large meshed gillnet fishery and of these, LOT was the predominant species. Higher CPUE values were spread across the Kathiawad Peninsula (Fig.17) while the highest 


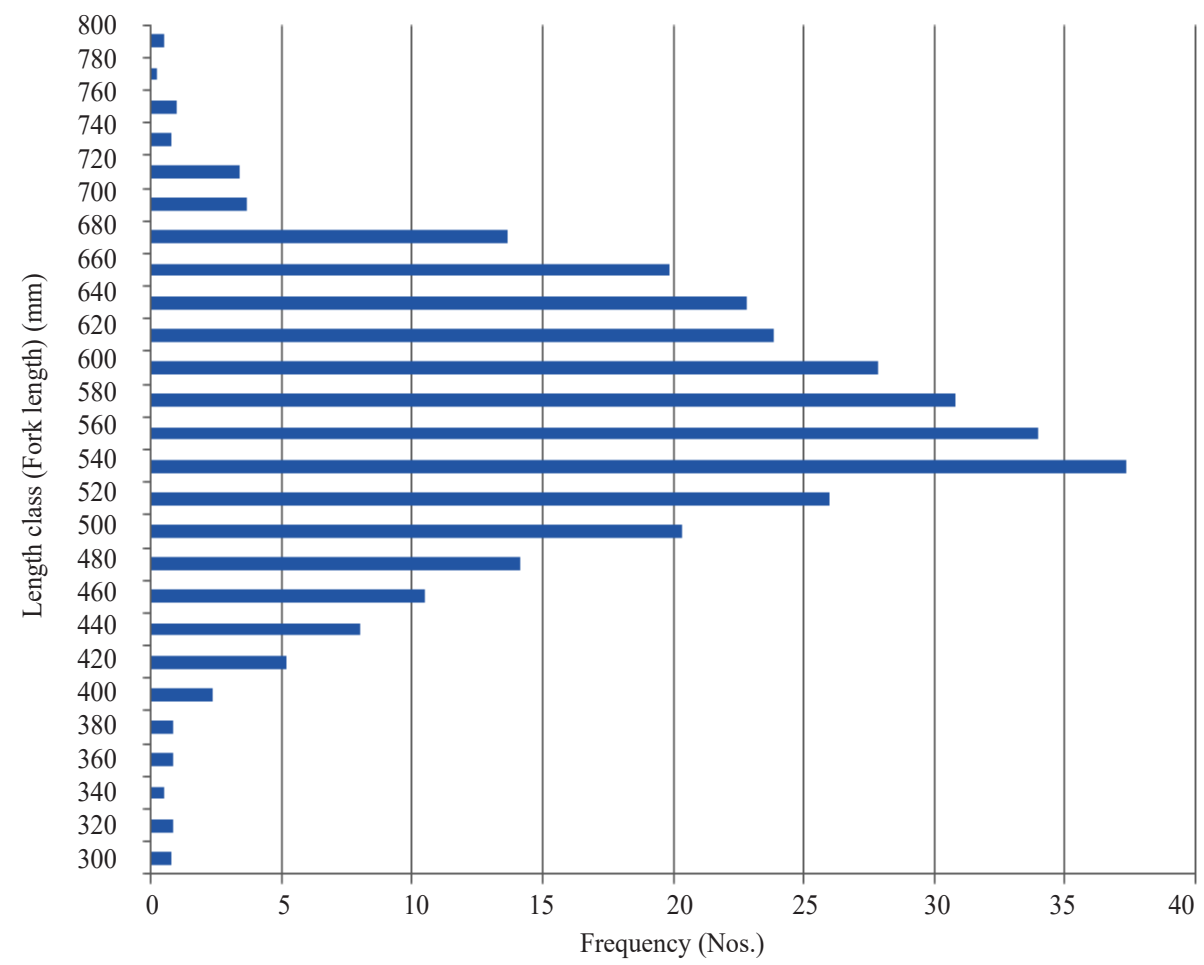

Fig. 13. Frequency of size classes in the longtail tuna fishery $(2008-16)(n=2387)$

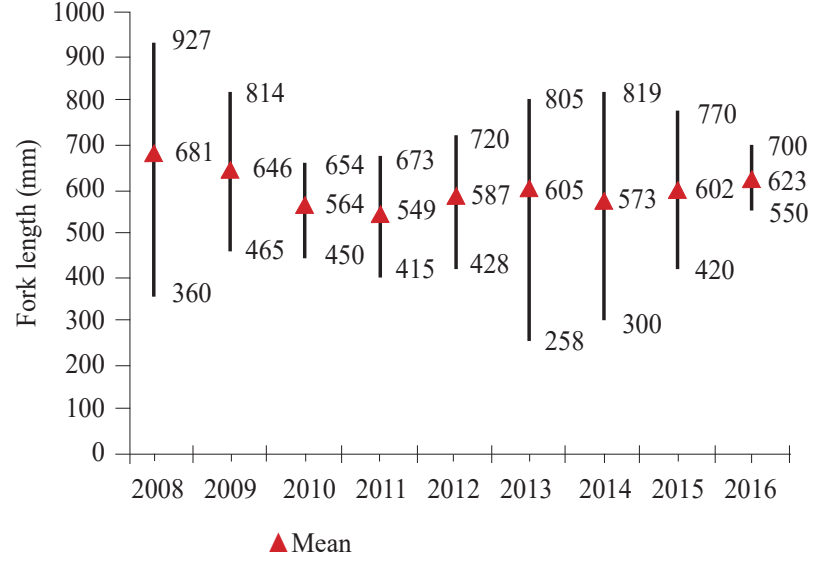

Fig. 14. Size ranges of longtail tuna landed in Gujarat during 2008 to 2016

CPUE values for LOT were limited to the areas between Veraval and Porbander ranging in depths from 20 to $100 \mathrm{~m}$ (Fig. 18). The incidence of LOT beyond $200 \mathrm{~m}$ depth contour was sparse while, other coastal tunas like the kawakawa and frigate tunas were abundant at times in such areas.

\section{Seasonal difference in abundance of LOT}

LOT formed a part of gillnet catches with varying catch rates throughout the year. The fishing

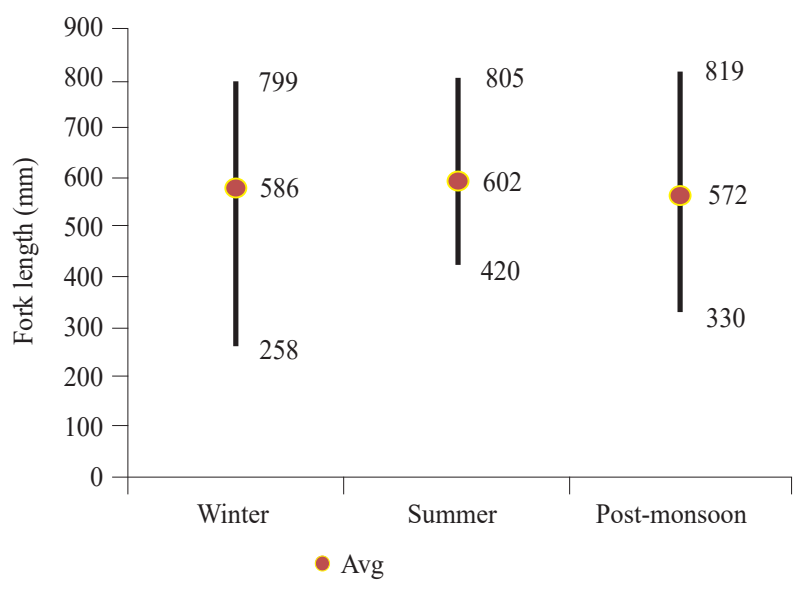

Fig. 15. Seasonal variation in size composition of longtail tuna landed in Gujarat (2012-16)

season commenced from end of August and extended upto May. Bulk of the landing occurred during the post-monsoon months (September to November) and winter months (December to February). Spatial expanse of fishing effort and the CPUE varied across the seasons (Fig. 19 a-d). Vigorous fishing occurs during post-monsoon months spread out all along the coast from off Kachh to off South Saurashtra between depths ranging from $20 \mathrm{~m}$ to very deep waters beyond the shelf. The highest CPUE (40 nos. per hour) was obtained at depth zone between 


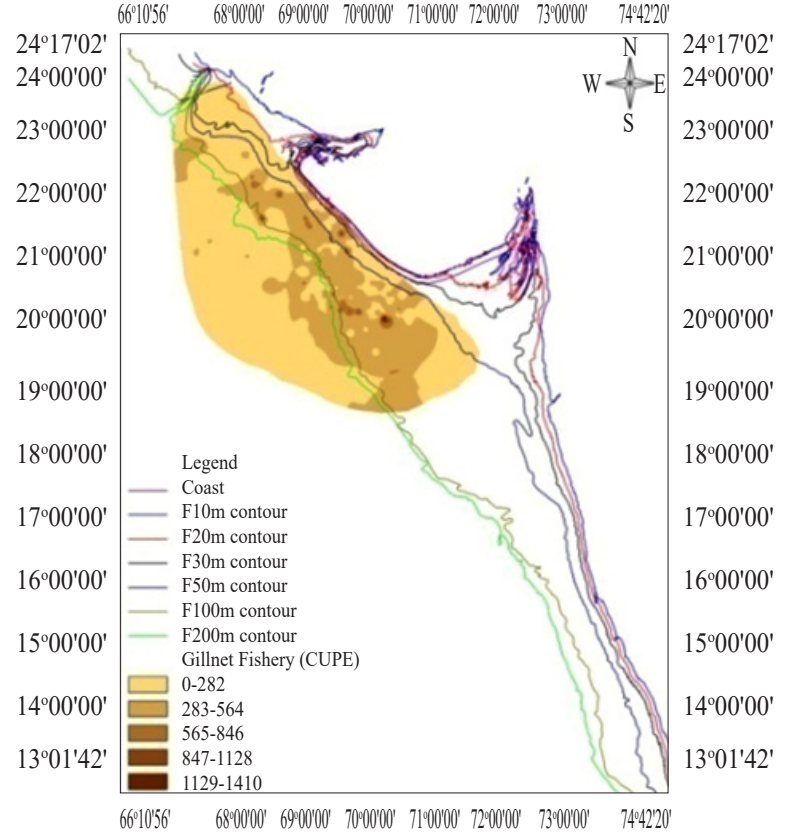

Fig. 16. Map showing the spread of gillnet fishing grounds off Gujarat

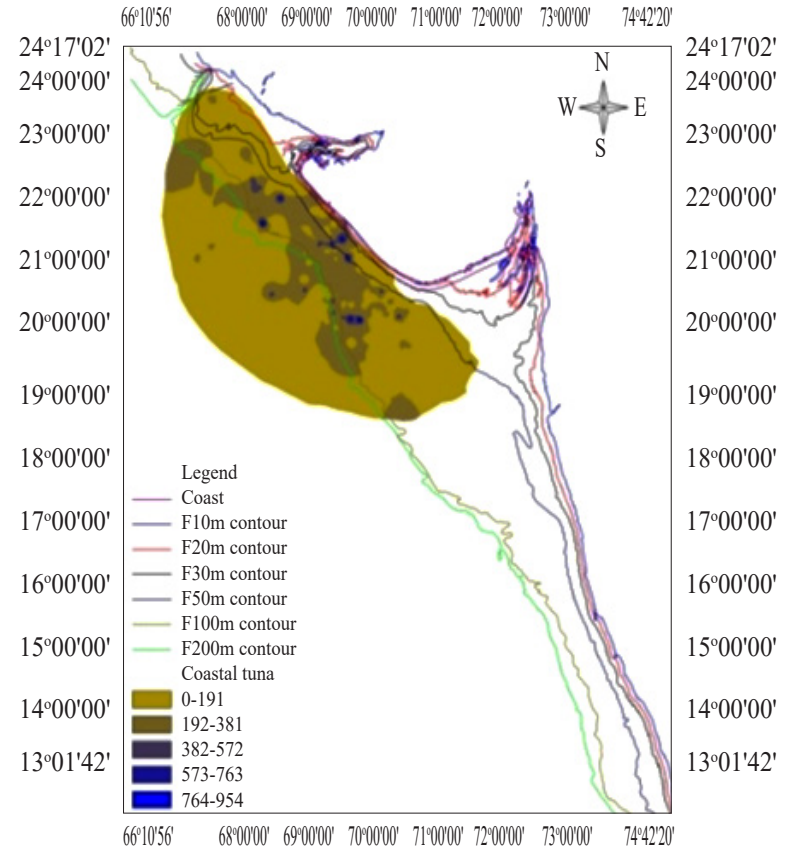

Fig. 17. Map showing the areas of abundance of neritic tunas

$50 \mathrm{~m}$ and $200 \mathrm{~m}$ off Veraval. CPUE values were higher in the Saurashtra Coast as compared to other regions.

During the winter months, the fishing and the areas with higher CPUE was typically restricted to the central Saurashtra at depths starting from $20 \mathrm{~m}$ onwards. The

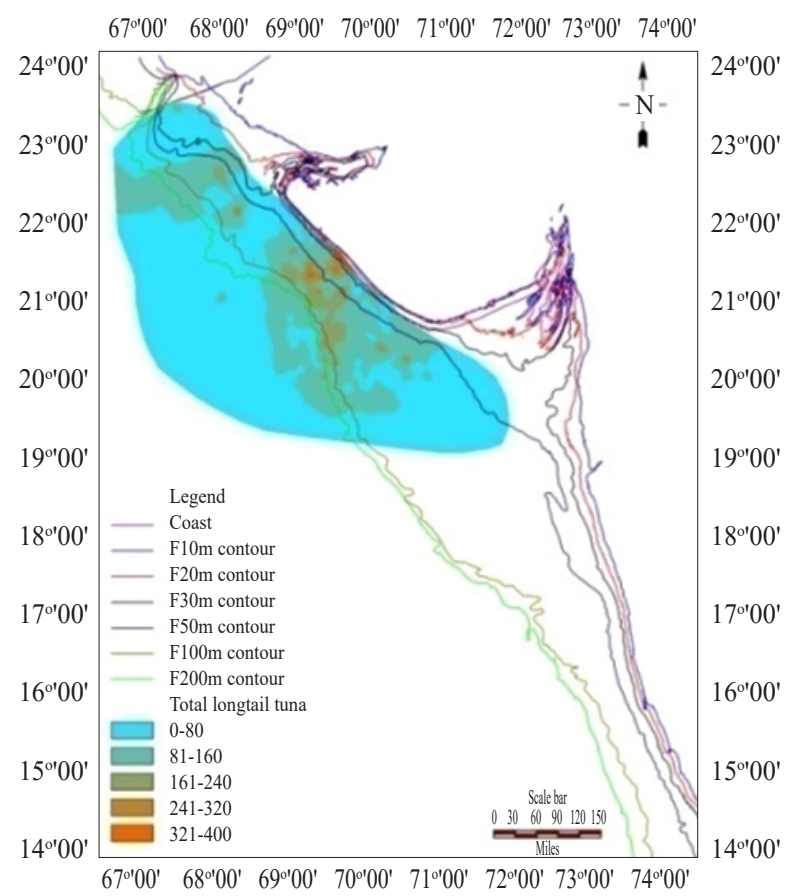

Fig. 18. Map showing the abundance pattern of longtail tuna

highest CPUE values (35 nos. per hour) occurred off Porbander at depths zones around $50 \mathrm{~m}$ and very high CPUE values occurred as close as $20 \mathrm{~m}$ during this season. Though high catch occurred in shallow waters during winter, at times when the catch was poor, the fishermen ventured to deeper waters too.

Generally, the catch and catch rates were poor in summer compared to other two seasons and the fishing for LOT during summer time was limited to Saurashtra up to south Gujarat. Fishermen extended their fishing off Gulf of Khambhat only in the summer months. Fishing occurred typically beyond $30 \mathrm{~m}$ depth zone unlike other seasons and the highest CPUE values (20 nos. per hour) were obtained at depths around $200 \mathrm{~m}$ and beyond.

There were only few fishing trips during the monsoon months, limited mainly to later days in August, when the weather was fair. The fishermen in Gujarat (across all the craft and gear types) tend to start their fishing immediately after the south-west monsoons when weather conditions improved. It can be seen that the fishing was restricted to the vicinities of Veraval from $10 \mathrm{~m}$ depth to over $50 \mathrm{~m}$ deep zones in this season. Fishing never exceeded the $100 \mathrm{~m}$ depth zones during monsoon. The catch rates were better (26 nos. per hour) around $50 \mathrm{~m}$ depth zones.

The spatial distribution of different ontogenetic stages of the LOT varied during different seasons. Fig. 20 (a-i) provide the seasonal distribution pattern of the different size groups viz., the small, medium and large LOT during 


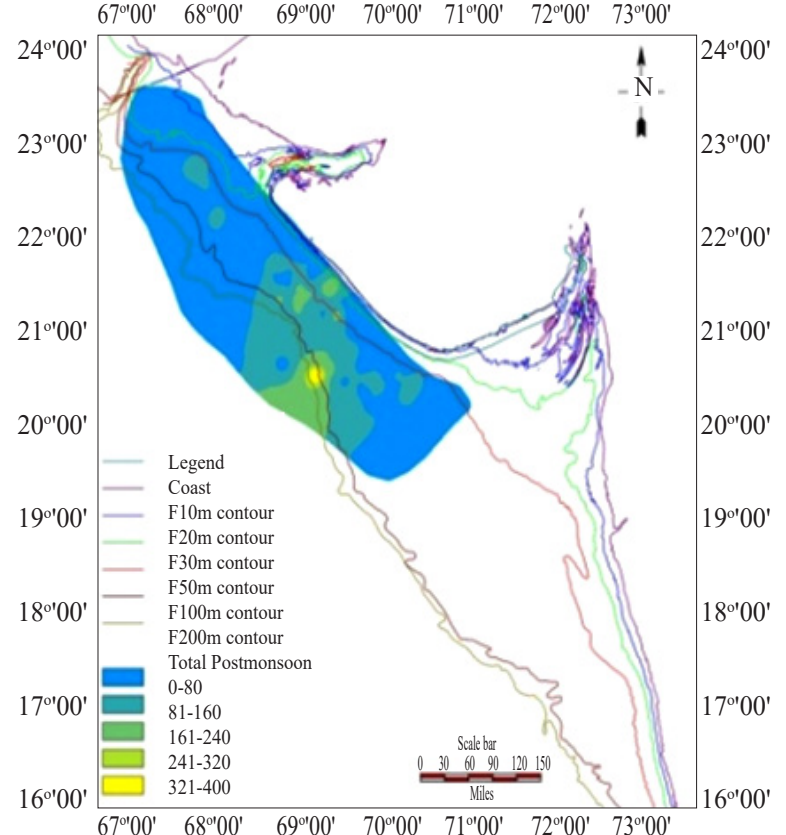

(a)

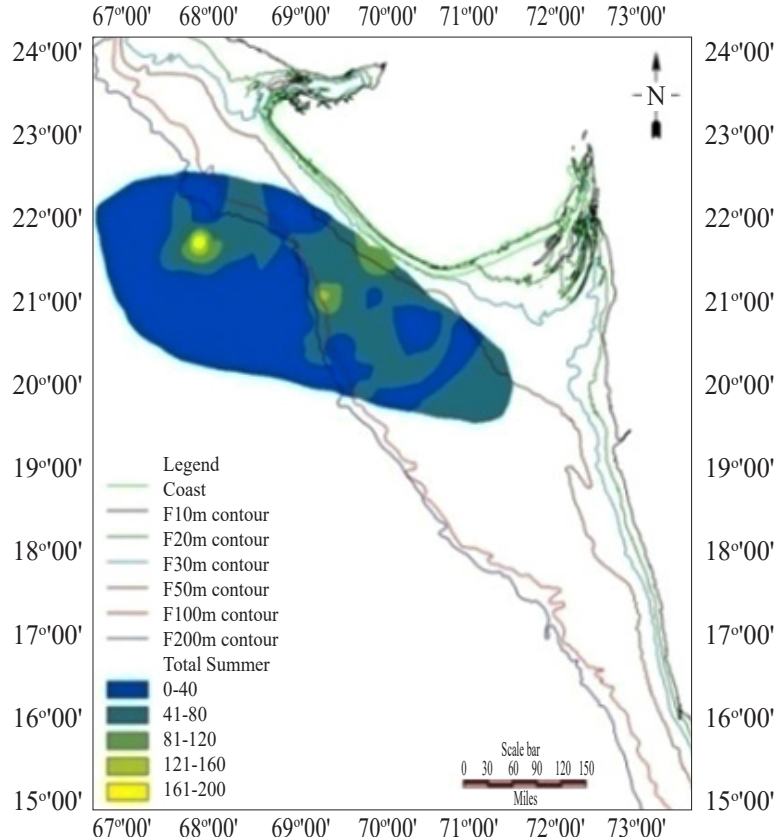

(c)

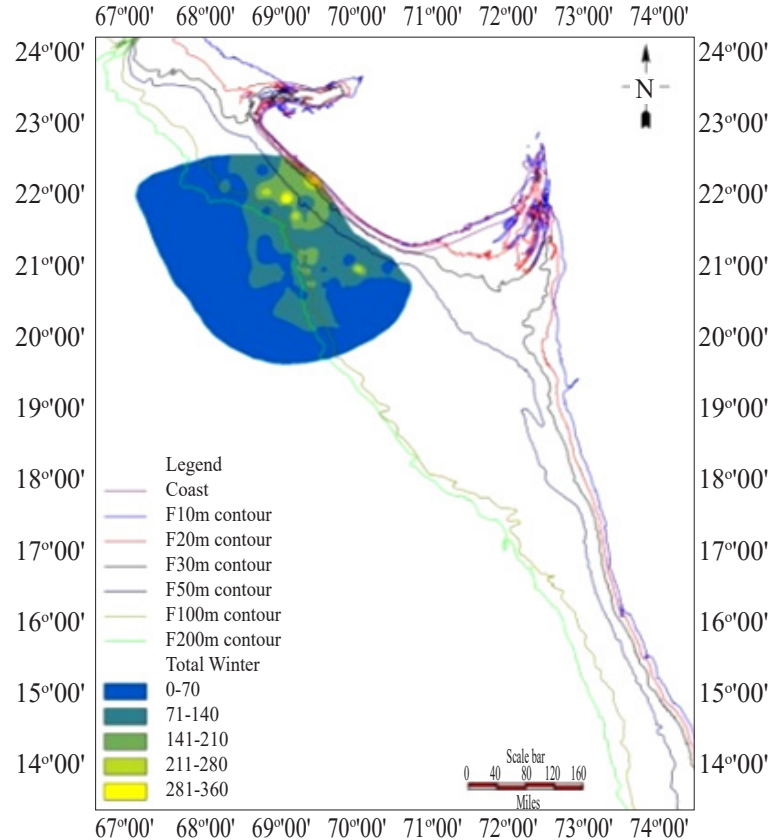

(b)

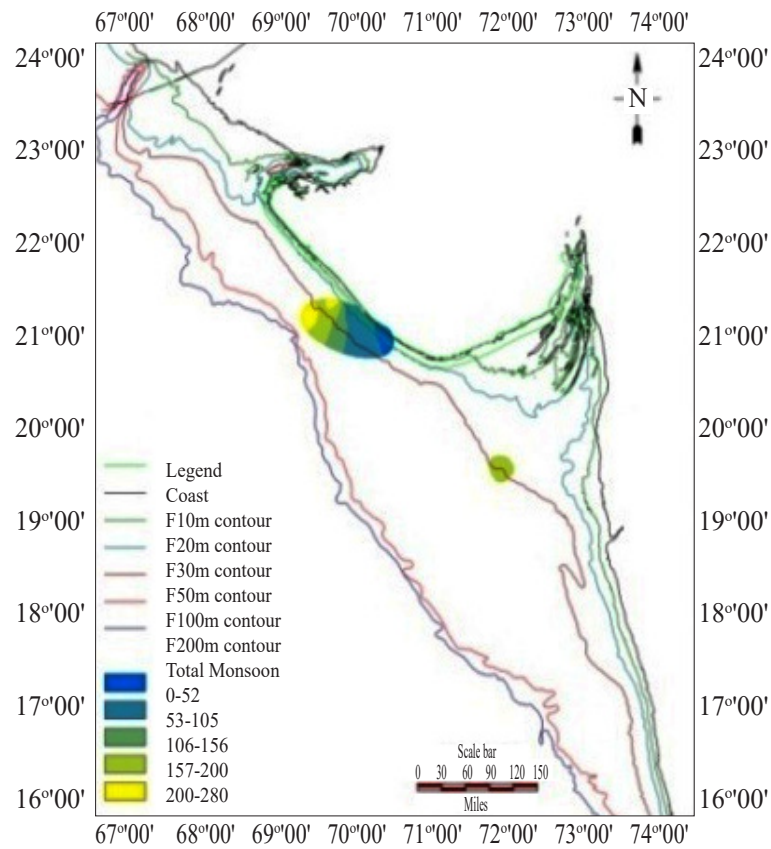

(d)

Fig. 19. Maps showing the abundance pattern of LOT during different seasons. a: Post-monsoon, b: Winter, c: Summer, d: Monsoon

post-monsoon (June-Aug), winter (Nov-Feb) and summer (March-May) months. Since numbers of samples were small, data during monsoon period was not considered for this analysis. Though smaller size groups occurred in the catch, their proportion was insignificant $(2 \%)$. The medium (35\%) and large (63\%) size groups formed the major catch at varying rates across the seasons.
The size-wise distribution also followed the pattern of the general LOT distribution as detailed above with more fishes occurring in shallow areas during winter and deeper areas during the summer. The smaller and medium sized LOTs were available in the inshore areas of southern Saurashtra coast while the larger ones were available in all depths, especially in the deeper areas throughout the coast of Gujarat. Large sized tunas occurred in deeper waters in 


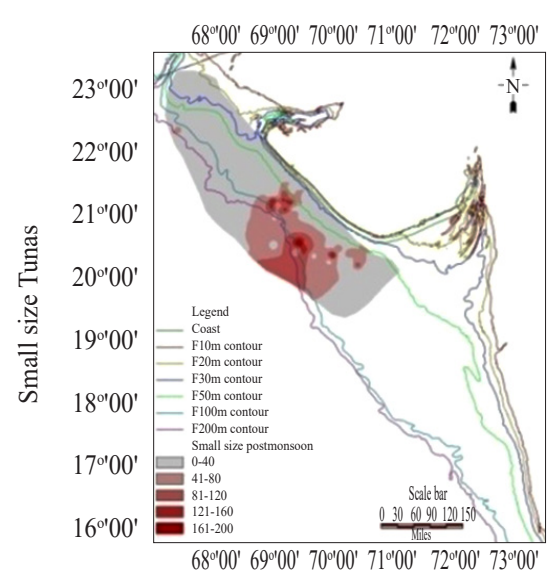

(a)

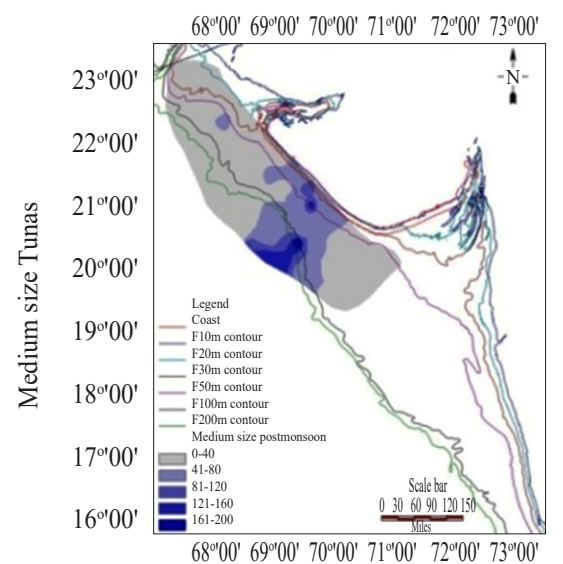

(d)

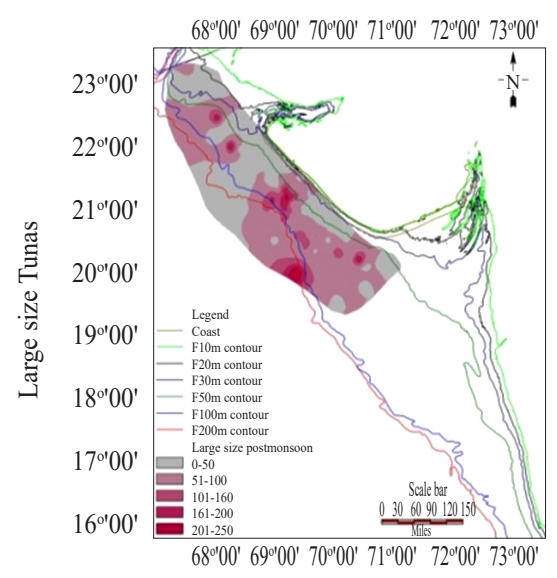

(g)

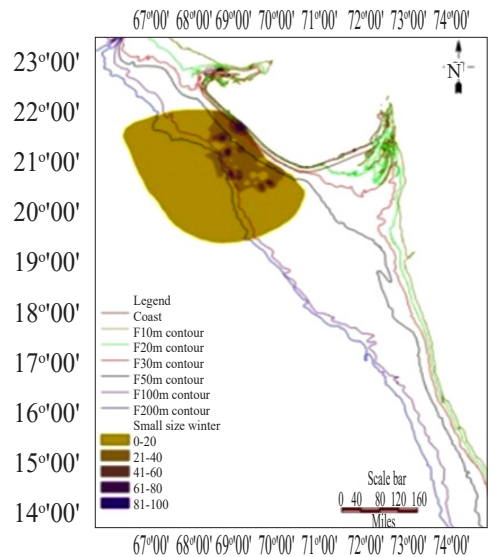

(b)

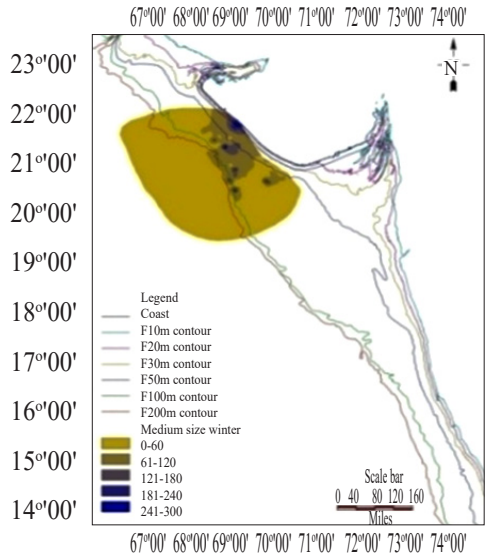

(e)

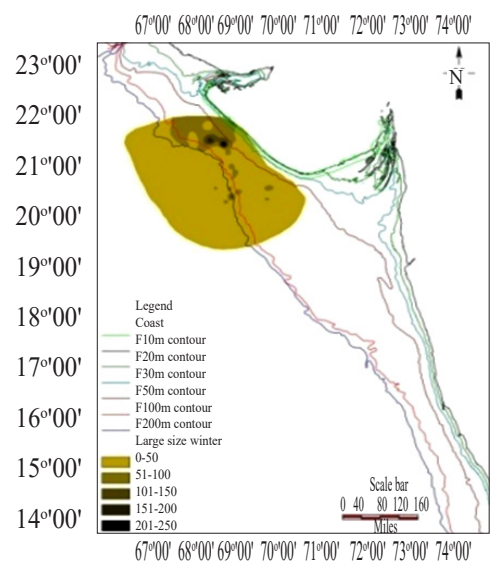

(h)

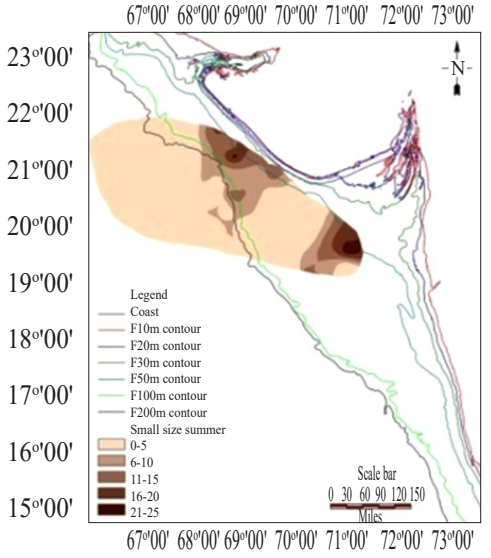

(c)

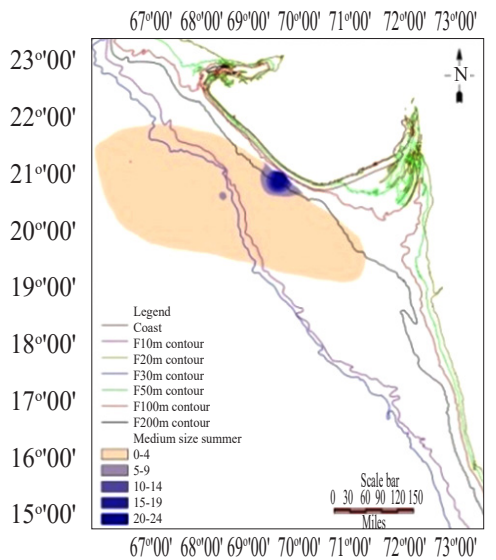

(f)

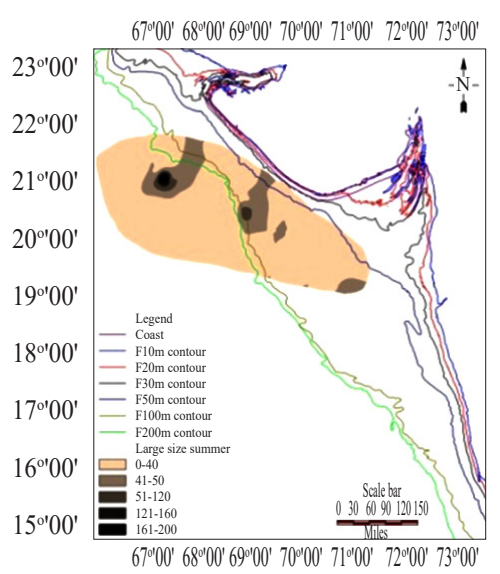

(i)

Summer

Fig. 20. Map showing the abundance pattern of different sizes of LOT over different seasons

northern Saurashtra especially during post-monsoon and winter months.

\section{Discussion}

Northern Arabian Sea is considered to be one of the major fishing areas for LOT globally. Iran (Islamic Republic) is the major contributor of LOT in the northern
AS with nearly $60 \%$ of the total catch during 2016 followed by Indonesia, India, Pakistan, Oman, Malaysia, Thailand and others. Spatio-temporal distribution of LOT along the north-west coast of India was studied for the first time and the study revealed the movement and seasonal abundance of the LOT in these waters. Yesaki (1991) considered extent of CS to be a limiting factor for global distribution 
of LOT. The results of the present study however indicated that the area of CS alone did not decide the quantity of LOT landing by different countries. Though India has the largest extent of CS, it is at $4^{\text {th }}$ position in LOT landing. Better productivity of Persian Gulf, the Oman Sea and the northern Arabian Sea coupled with the differential fishing effort could be the major reason for the variation in catch. Detailed information on fishing effort expended in each region would more accurately reveal differential abundance of LOT in the region.

LOT is distributed all along the Indian coast and the Island territory of Andaman and Nicobar Islands with west coast accounting for nearly $93 \%$ and north-west coast (Gujarat and Maharashtra) nearly $83 \%$ of the total catch during 2006-2010 (Rohit et al., 2011; Abdussamad et al., 2012). In India, the fishery was almost exclusively by drift gillnets. LOT was the major tuna species and an average of $3869 \mathrm{t}$ was landed in Gujarat during 1980-2012. The dominance of LOT species in total tuna catch has been reported earlier by Ghosh et al. (2010) and Abdussamad et al. (2012). The steady increase in LOT landing from 1990s through 2000s and the increased catch rate may be attributed to several reasons and includes improvements in fishing techniques like the introduction and widespread use of efficient nylon monofilament nets as suggested by Thomas (2010); replacement of the small meshed $(<85 \mathrm{~mm})$ demersal oriented gillnet fishing in shelf areas to a more resilient pelagic fishing by adopting larger meshed (>140 mm) pelagic gillnet (Kasim and Khan, 1986; Polara et al., 2014) and continued expansion of the fishing areas to beyond $50 \mathrm{~m}$ depth zone which was possible due to the introduction of more number of larger (16 m OAL) dedicated gillnetters (locally known as Bethada) fitted with higher engine power and equipped with navigation and communication aids (Polara et al., 2014).

Observation of higher mean size and a narrow size range during summer months and incidence of large size fishes in the outer neritic realms of the shelf during the same period indicate a possible movement of fishes to outer shelf areas during the summer months as they grow larger. Port based sampling has revealed some unique features of distribution of the species like the differences in abundance pattern, differential distribution of size groups along the range of its distribution horizontally and vertically. Such differential distribution of different sized LOT has been reported off the east and west coasts of Australia (Serventy, 1956; Wilson, 1981) and Japan (Nakamura, 1969; Fukusho and Fujita, 1972). Yesaki (1982) reported size group differences in distribution with respect to inner and outer neritic regime along the Phuket coast. Progressive increase in mean length of LOT along the eastern Arabian Sea starting from the south-west coast $(50 \mathrm{~cm})$ through the north-west coast of India $(61.9 \mathrm{~cm})$ to the Gulf of Oman $(74 \mathrm{~cm})$ was reported by Kaymaran et al., 2011 and Abdussamad et al. (2012) and the largest captured LOT (142 mm) was caught off Salalah, Oman (Al-Mamari et al., 2014).

Very little information is available on the movement of the fish throughout its distributional range. As such there are no information available on the movement of fish in the northern AS, principally owing to lack of long-term spatially referred commercial or experimental catch data for any gear. Organised tagging programme for studying the movement of the fish has not been reported anywhere except for two programmes in Australian waters. These tagging programmes have revealed that the species are capable of moving large distances in short time and provided some insight of its seasonal movement (Griffith et al., 2010). Results from the present spatially referred catch data collected with participation of the fishermen disclosed novel information on the spatial distribution of the LOT off Gujarat Coast and the expanse of fishing grounds. Highest abundance points of neritic tunas in general were spread to a wider area along the Saurashtra coast while that of the LOT was limited to the areas between Veraval and Porbander at depths ranging from 20 to $100 \mathrm{~m}$ and were absent in mouths of the Gulf of Khambhat and the Gulf of Kachh. These gulfs have typical geomorphology and coastal processes and are known for their high energy tide driven systems causing the areas to be turbid (John, 1979; Kunte et al., 2003; Kumar and Ashok, 2010). Suspended particles brought in by Narmada and Tapi rivers to the Gulf of Khambhat is kept in suspension by the tidal currents (Reghunathan et al., 2003) leading to persistent turbidity in the Gulf while fine grained sediments on the seafloor, strength of the tidal current and bathymetry are attributed to the turbidity in the Gulf of Kachh (Vethamony and Babu, 2010). Reghunathan et al. (2003) have reported that the clarity of water improved progressively from Gulf of Khambhat to Veraval. Increased Chlorophyll- $a$ content, phyto and zooplankton diversity and biomass of seaweed along Veraval as compared to the Gulf (Reghunathan et al., 2003) indicate availability of relatively transparent water along the coasts of Saurashtra. The absence of LOT in turbid waters of the gulf and presence along the Saurashtra Coast testified the basic tenet that LOT though typically a neritic species tend to avoid estuarine areas with high turbidity and low salinity (Collette and Nauen, 1983; Yesaki, 1991; Griffiths, 2010). Further, the higher catches of LOT in gillnets operated off Gujarat and poor catch of the species in the adjacent state of Maharashtra and other maritime states along the west coast indicated that the longtail tuna's chosen habitat along the coasts of 
India is situated off Gujarat. The results thus point to a fact that the dominance of the LOT along the eastern Arabian Sea starts from $20^{\circ} \mathrm{N}$ latitude onwards.

Differences in the spatial expanse of gillnet fisheries as well as the catch rates of LOT across the seasons were revealed in the present study. The areas with highest catch rates during the winter months are closer to shore at around $50 \mathrm{~m}$ depth contours and LOT was caught at depth zones as close as $20 \mathrm{~m}$. Visibility of the water may be a major factor influencing the movement of the fish on the shelf as the tunas rely heavily on their high visual acuity to capture prey (Nakamura, 1968). Nayak and Sahay (1985) reported that the suspended sediment concentration is higher during the monsoon season and it decreases considerably by winter when LOT catches are higher. Tuna movement is also known to be influenced by the sea surface temperature (SST). Optimum regions for tuna feeding are found to be the frontal boundaries where the biological factor (prey) and environmental conditions are optimum (Ramos et al., 1991). Occurrence of the higher catch rates of larger sized LOT in deeper areas during summer, supports the findings by some authors that the larger fishes move to offshore areas (Yesaki, 1982). Warmer months are known to be the spawning period for this species (Wilson, 1981; Griffiths et al., 2007; Abdussamad et al., 2012). A recent study on the biology of the species in this region (Mohammed Koya et al., 2018) also revealed that the spawning peaked in May-June. The hooking of the largest LOT off Salalah, Oman (Al-Mamari et al., 2014) indicated the availability of large fishes in deeper waters of the northern AS. Hence, it may be construed that the mature fishes move to the deeper waters in the oceanic realm probably for further gonadal development and spawning.

The above observations necessitates further studies on the influence of environmental factors such as the SST, chlorophyll and visibility on the distribution of LOT coupled with spatially referred biological studies to understand the habitat choice of the species at various life stages to manage the species more efficiently. The study sets a prelude to participatory collection of fisheries data in small scale and artisanal fisheries, where the scope of on-board observer based monitoring is relatively difficult. Integration of video documentation, electronic reporting and strengthened port observations will enhance the quality of such data and will pave way for developing an inclusive and cost effective fisheries monitoring and management system for the small scale and artisanal fisheries in the region.

\section{Acknowledgements}

Authors thankfully acknowledge the support and guidance rendered by Dr. A. Gopalakrishnan, Director,
ICAR-CMFRI, Kochi. Support rendered by the technical and supporting staff at Regional Centre of ICAR-CMFRI, Veraval, Gujarat is thankfully acknowledged.

\section{Reference}

Abdussamad, E. M., Said Koya, K. P., Shubhadeep Ghosh, Prathibha Rohit, Joshi, K. K., Manojkumar, B., Prakasan, D., Kemparaju, S., Elayath, M. N. K., Dhokia, H. K., Manju Sebastine and Bineesh, K. K. 2012. Fishery, biology and population characteristics of longtail tuna, Thunnus tonggol (Bleeker, 1851) caught along the Indian coast. Indian J. Fish., 59(2): 7-16.

Al-Mamari, D., Al-Kharusi, L., Al-Kiyumi, F., Al-Shogebai, S., Al-Anboori, I., Al-Seneadi, R. and Khrorv, S. 2014. Record of the largest size of longtail tuna, Thunnus tonggol (Bleeker 1851) from off shore Salalah in the Sultanate of Oman. J. Fish., 2(3): 215-216. DOI: dx.doi.org/10.17017/ jfish.v2i3.2014.57.

Azeez, A., Mohammed Koya, P., Mathew, K. L., Temkar, G. S. and Khileri, R. A. 2016. GIS based mapping of spatiotemporal distribution pattern of ribbonfish Trichiurus lepturus (Linnaeus, 1758) along Saurashtra Coast, India. Indian J. Fish., 63(4): 10-14. DOI: 10.21077/ijf.2016.63. 4.52912-02.

Collette, B. B. and Nauen, C. E. 1983. FAO species catalogue. vol. 2. Scombrids of the world. An annotated and illustrated catalogue of tunas, mackerels, bonitos and related species known to date. FAO Fisheries Synopsis 125, 137 pp.

Fukusho, K. and Fujita, S. 1972. Notes on the young tunas referred to the Genus Thunnus caught in the waters of Tsushima Island. Jap. J. Ichthyol., 19(1): 34-35.

Ghosh Subhadeep, Pillai, N. G. K. and Dhokia, H. K. 2010. Fishery, population characteristics and yield estimates of coastal tunas at Veraval. Indian J. Fish., 57(2): 7-13.

Griffiths, S. P., Fry, G. C., Manson, F. J. and Pillans, R. D. 2007. Feeding dynamics, consumption rates and daily ration of longtail tuna (Thunnus tonggol) in Australian waters, with emphasis on the consumption of commercially important prawns. Mar. Freshw. Res., 58: 376-397. doi.org/10.1071/ MF06197.

Griffiths, S. P., Fry, G. F., Manson, F. J. and Lou, D. C. 2010. Age and growth of longtail tuna (Thunnus tonggol) in tropical and temperate waters of the central Indo-Pacific. ICES J. Mar. Sci., 67: 125-134. doi.org/10.1093/icesjms/fsp223.

IOTC-WPNT07. 2017. Report of the $7^{\text {th }}$ Session of the IOTC Working Party on neritic Tunas. Male, Maldives, 10-13 July 2017. IOTC-2017-WPNT07-R [E], 93 pp.

John, V. J., Srivastava, P. S. and Malhotra, A. K. 1979 Oceanographic studies off Narara Bet, Gulf of Kachh. Indian J. Mar. Sci., 8: 20-26.

Kasim Mohammed, H. and Khan, Mohammad Zafar 1986. A preliminary account of the gillnet fishery off Veraval during 1979-82. Indian J. Fish., 33(2). p. 155-162. 
Kaymaran, F., Darvishi, M. F., Parafkandeh, Sh. Ghasemi and Talebzadeh, S. A. 2011. Population dynamic parameters of Thunnus tonggol in the north of the Persian Gulf and Oman Sea IOTC-2011WPNT01-18.

Kumar Sanil, V. and Ashok Kumar, K. 2010. Waves and currents in tide dominated location off Dahej, Gulf of Khambhat, India. Mar. Geol., 33(2): 218-231.

Kunte, P. D., Wagle, B. G. and Yasuhiro Sugimori 2003. Sediment transport and depth variation study of the Gulf of Kachh using remote sensing. Int. J. Remote Sens., 24(11): 2253-2263.

Mohammed Koya, K., Prathibha Rohit, Abdussamad, E. M., Abdul Azeez, P., Vinay kumar Vase and Sangita Bharadiya 2018. Reproductive biology, diet and feeding pattern of longtail tuna Thunnus tonggol (Bleeker, 1851) in the northeastern Arabian Sea off Gujarat, India, Indian J. Fish., 65(2): 16-25. DOI: 10.21077/ijf.2018.65.2.78457-02.

Nakamura, E. L. 1968. Visual acuity of two tunas, Katsuwonus pelamis and Euthynnus affinis. Copeia 1968 (1): 41-49. doi: $10.2307 / 1441548$

Nakamura, I. 1969. Big catches of longtail tuna in Wakasa Bay, Japan. Jap. J. Ichthyol., 15: 160-161. doi.org/10.11369/jji 1950.15 .160

Nayak Shailesh, R. and Baldev Sahai 1985. Coastal morphology: a case study of the Gulf of Khambhat (Cambay). Int. J. Remote Sens., 6(3-4): 559-567. doi.org/10.1080/0143116 8508948478 .

Polara, J. P., Swatipriyanka Sen Dash, Gyanaranjan Dash, Savariya, Y. D., Dhokia, H. K. and Mohammed Koya, K. 2014. Evolution in fishing crafts and gears of the Saurashtra coast. Mar. Fish. Infor. Serv., T \& E Ser., 220: 8-10.

Ramos, A., Sangra, P., Hemandez-Guerra, A. and Canton, M. 1991. Large and small scale relationships between Skipjack tuna (Katsuwonus pelamis) and oceanographic features observed from satellite imagery of the Canary Island area. ICES $79^{\text {th }}$ statutory meeting, ICES, Copenhagen, Denmark.

Reghunathan, C., Tewari, A., Joshi, H. V., Sravan Kumar, V. G., Trivedi, R. H. and Yasmin Khamhaty 2003. Impact of turbidity on the intertidal macrofauna at Gopinath, Mahuva and Veraval coasts (West Coast of India). Indian J. Mar. Sci., 32(3): 214-221.

Rivoirard, J., Simmonds, J., Foote, K. G., Fernades, P. G. and Bez, N. 2000. Geostatistics for estimating fish abundance. Blackwell Science, Oxford, 206 pp.

Rohit, P., Abdussamad, E. M., Said Koya, K. P., Sivadas, M. and Ghosh, S. 2011. Tuna fishery of India with special reference to biology and population characteristics of neritic tunas exploited from Indian EEZ. IOTC-2011-WPNT01-10.

Serventy, D. L. 1956. Additional observations on the biology of the northern blue fin tuna Kishinoella tonggol (Bleeker), in Australia. Aust. J. Mar. Freshw. Res., 7: 44-63.

Thomas Saly, N. 2010. Gillnet fishing in India In: Meenakumari, B., Boopendranath, M. R., Edwin, L., Sankar, T. V., Gopal, N. and Ninan, G. (Eds.), Coastal fishery resources of India: Conservation and sustainable utilisation. Society of Fisheries Technologists (India), Kochi, p. 1-13.

Vethamony, P. and Babu, M. T. 2010. Physical processes in the Gulf of Kachh: A review Indian J. Geo-Mar. Sci., 39(4): 497-503.

Wilson, M. A. 1981. The biology, ecology and exploitation of longtail tuna, Thunnus tonggol (Bleeker) in Oceania. Macquarie University, New South Wales, 195 pp.

Yesaki, M. 1982. Thailand biological and environmental observations. A report prepared for the pole-and-line tuna fishing in southern Thailand project. FAOFI: DP/THA/77/ 008: Field Doc., 3: 46.

Yesaki, M. 1989. Estimates of age and growth of kawakawa (Euthynnus affinis), longtail tuna (Thunnus tonggol) and frigate tuna (Auxis thazard) from the Gulf of Thailand based on length data. Indo-Pac. TunaDev. Mgt. Programme, IPT P /89/GEN/17, p. 94-108.

Yesaki, M. 1991. A review of the biology and fisheries of the longtail tuna (Thunnus tonggol) in the Indo-Pacific region. FAO Fisheries Technical Paper, 336: 370-387. 